\title{
Üç-implant-destekli mandibular overdenture protezlerde çeşitli bar tasarımlarının stres iletim karakterlerinin değerlendirilmesi
}

\author{
Emre Tokar, ${ }^{1 *}$ Serdar Polat, ${ }^{1}$ Bülent Uludağ ${ }^{2}$ \\ ${ }^{1}$ Protetik Diş Tedavisi Anabilim Dalı, Diş Hekimliği Fakültesi, \\ Gazi Üniversitesi, ${ }^{2}$ Özel Uludağ Ağız ve Diş Sağlığı Polikliniği, \\ Ankara, Türkiye
}

\section{ÖzeT}

AmAÇ: Dişsiz mandibulaya sahip hastaların tedavisinde implant-destekli overdenture protezler konvansiyonel tam protezlerin yerine sıklıkla tercih edilmektedirler. Bu çalışmanın amacı, dört farklı bar tutucu tasarımına sahip üç-implant-destekli mandibular overdenture protezlerin stres iletim karakterlerini incelemektir.

Gereç VE YöNTEM: Dişsiz mandibular bir modelden interforaminal bölgesine üç implantın (3.75 mm - 13 $\mathrm{mm}$ ) yerleştirildiği bir fotoelastik mandibular model hazırlandı. Bu model üzerine dört farklı bar tasarımı olan mandibular overdenture yapıldı: bar klips, bar-galvano, bar-locator ve bar-ceka. Her bir overdenture tasarımında, sağ birinci molar dişin santral fossasına vertikal yükleme (135 N) yapıldı. Stres konsantrasyonları fotoğrafik olarak kaydedildi ve görsel olarak analiz edildi.

BULGULAR: Çalışmada kullanılan bar tutucu tasarımları düşük ve orta derecelerde stres gösterdi. En düşük stres bulgusu bar klips tasarımında bulunurken, bar-locator, bar-ceka ve bar-galvano tasarımları bunu takip etti.

SoNuç: Uygulanan yükler bütün implantlara dağıtılmıştır. Çalışmada değerlendirilen tasarımlar yükleme yapılan taraftaki implantın çevresinde orta derecede strese sebep olmuştur. Bar tutucunun distallerine stud tutucu uygulaması ve elektroforming yüzey işlemi implantların çevresindeki stresi arttırabilir.

Anahtar Kelimeler: Dental stres analizi; implant-destekli diş protezi; Hassas tutuculu protez; Protez, geçmeli

Kaynak Göstermek İçin: Tokar E, Polat S, Uludağ B. Üç-implant-destekli mandibular overdenture protezlerde çeşitli bar tasarımlarının stres iletim karakterlerinin değerlendirilmesi. Acta Odontol Turc 2017;34(1):8-13

ЕрітӧR: Ufuk Hasanreisoğlu, Ankara Üniversitesi, Ankara, Türkiye

Makale gönderiliș tarihi: 31 Mayıs 2016; Yayına kabul tarihi: 27 Temmuz 2016 *iletişim: Dr. Emre Tokar, Gazi Üniversitesi, Diş Hekimliği Fakültesi, Protetik Diş Tedavisi Anabilim Dalı, 8. Cadde, 06510, Emek, Ankara, Türkiye;

E-posta: emretokar@yahoo.com
YAYIN HAKKI: () 2017 Tokar ve ark. Bu eserin yayın hakkı Creative Commons Attribution License ile ruhsatlandırılmıştır. Sınırsız kullanım, dağıtım ve her türlü ortamda çoğaltım, yazarlar ve kaynağın belirtilmesi kaydıyla serbesttir.

[Abstract in English is at the end of the manuscript]

\section{GiRiş}

Implant-destekli overdenture protezler (IDO) tam dişsizlik olgularında konvansiyonel tam protezlere alternatif olarak kullanılan etkili bir tedavi seçeneğidir. Hatta günümüzde, tam dişsiz alt çeneler için implantdestekli overdenture'lerin ilk seçenek olarak hastaya sunulması tavsiye edilmektedir. ${ }^{1-3}$ Alt çenede overdenture protezler için iki veya daha fazla implanttan destek alınması önerilmektedir. ${ }^{4,5}$ Üç veya daha fazla sayıda implanttan destek alınarak hazırlanan overdenture protezlerde tutuculuk ve stabilitenin daha iyi olduğu ifade edilmektedir. ${ }^{6}$

İmplant-destekli overdenture için kullanılan hassas tutucu çeşitleri temel olarak dört ana başlıkta incelenebilir. Bunlar; bar, stud, manyetik ve teleskopik tutuculardır. ${ }^{7} \mathrm{Bu}$ hassas tutucu çeşitleri vakanın durumuna göre tek başlarına kullanılabilirken, birbirleriyle kombine şekilde de kullanılabilmektedir. ${ }^{8,9}$ Diş hekimleri genellikle iDO vakalarında bar veya stud tutucuları tercih etmektedirler. ${ }^{7,10}$ Bar tutucular, tek başlarına kullanılabilecekleri gibi stud tutucularla kombine edilerek de kullanılabilirler. Bu tip tutucular hem esnek hem de rijit tasarıma olanak vermesi sebebiyle IDO vakalarında geniş bir kullanım alanına sahiptirler. ${ }^{11}$ Kullanılacak hassas tutucu seçiminde alveol kemiği, kas bağlantılarının aktivitesi, tutuculuk, çiğneme kuvvetinin etkinliği ve hasta kaynaklı faktörler göz önünde bulundurulmalıdır., ${ }^{6,12}$ Tercih edilen tutucu sistemin tutuculuk ve stabilite özelliklerinin yanı sıra stres dağılımına olan etkisi de düşünülmelidir.

Başarılı protetik tedavi için okluzal yükler, implantlar ve protez destek sahaları arasında dengeli olarak dağıtıımalıdır. Çünkü, aşırı yükler implant çevresindeki kemik rezorpsiyonunu tetikleyebilir, bu durum implant kaybına neden olabilir. ${ }^{13,14}$ Implant-destekli overdenture

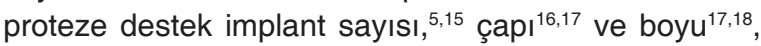


implantların konumu ${ }^{15,19-21}$ ve açısı ${ }^{22,23}$, hassas tutucu

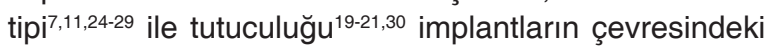
kemiğe ve protez destek sahalarına iletilen stresleri etkileyebilir.

Çalışmamızın amacı, üç-implant-destekli dört farklı bar tasarımlı mandibular overdenture protezlerin stres dağılımına etkisini fotoelastik stres analizi yöntemi ile değerlendirmektir.

\section{Gereç VE Yöntem}

Tam dişsiz alt çeneye sahip bir hastadan alınan ölçüden model elde edildi. Bu modelin tabanı mumla uzatıldı. Elastomerik bir ölçü maddesiyle (Zetaplus, Zhermack, Polesine, İtalya) ölçüsü alınarak alçıdan tüm model elde edildi. Elde edilen yeni alçı modelin, yine aynı elastomerik ölçü maddesi kullanılarak (Zetaplus) ölçüsü alındı. Bu ölçü içerisine modelaj mumu (Poliwax, Bilkim Kimya, İzmir, Türkiye) dökülerek alçı modelin mum duplikatı elde edildi. Mum model üzerinde terminal implantlar arası mesafe, doğal kanin dişler arası mesafede olduğu gibi $22 \mathrm{~mm}$ olarak belirlendi. Üçüncü implantın ise tam orta bölgede konumlandırılması planlanarak, orta hatta paralel olarak yerleştirildi. Mum model üzerinde belirtilen yerlere implantlar $(3.75 \mathrm{~mm}$ - $13 \mathrm{~mm}$, Zimmer Dental, Carlsbad, CA, ABD) paralelometre (Ney Surveyor; Dentsply Intl, York, PA, ABD) yardımıyla yerleştirildi. Oluşturulan implantlı mum modellerin elastomerik ölçü maddesiyle (Zetaplus) ölçüsü alındı. Sıcak su dökülerek mum uzaklaştırıldı, içinde implantların kaldığı negatif kalıp elde edildi. Bu kalıp içerisine fotoelastik rezin (PL-2, Measurement Group Inc, Wendell, NC, ABD) üretici talimatlarına uyularak döküldü ve fotoelastik rezinden model elde edildi. Elde edilen model üzerine 4 farklı bar tasarımı (bar klips, bar-galvano, barceka ve bar-locator) üretildi. Fotoelastik modelde implantlara ölçü kopingleri (Zimmer Dental) bağlandı. Elastomerik ölçü maddesi (Zetaplus) ile fotoelastik modelin ölçüsü alındı. Ölçü kopingleri implantlardan ayrılıp implant analoglarına (Zimmer Dental) bağlandı ve ölçü içerisindeki yerlerine yerleştirildi. Ölçüye alçı (Begostone, Bego Dental, Bremen, Almanya) dökülerek model elde edildi. Mukoza boşluğunu taklit etmesi için modelde serbest sonlanan kısımlara $3 \mathrm{~mm}$ kalınlığında bas plak (Cavex Dental, Base Plates, Cavex, Haarlem, Hollanda) adapte edildi.

Barların hazırlığında basamaklı destekler (Zimmer Dental) implant analoglarının üzerine yerleştirildikten sonra plastik dökülebilir parçalar (Zimmer Dental) bu desteklere vidalandı. Plastik parçaların boyları kısaltıldı ve plastik prefabrik barlar (Round Bar, Bredent $\mathrm{GmbH}$, Senden, Almanya) implantlar arasındaki mesafeye uygun olarak kesilip mum ile plastik dökülebilir parçalara tutturuldu. Elde edilen bar modelajları modelden çıkartılıp, Co-Cr alaşımdan (Biosil, Degussa, Hanau, Almanya) dökümü yapıldı. Bar-locator ve barceka tasarımlarında hazırlanan bar modelajlarının distallerine bu stud tutucular lehimlendi. Tutucuların hazırlıkları tamamlandıktan sonra iskelet altyapı modelajları yapıldıktan sonra dökümleri gerçekleştirildi. Bar-galvano tasarımında, hazırlanan iskeletin iç yüzeyinde barın oturacağı alan elektroforming yöntemi ile altın kaplandı.

Protezlerin aynı dizime sahip olması için referans bir diş dizimi yapıldı. Mufla içerisine konulan elastomerik ölçü maddesi (Zetaplus) ile diş diziminin ölçüsü alındı. Modellerdeki andırkatlar doldurulduktan sonra modeller lak ile izole edildi. Silikondan elde edilen diş dizimin negatifinin içine şeffaf akrilik rezin (Meliodent, Heraeus Kulzer GmbH, Gruner, Hanau Postfach, Almanya) konuldu. Tutucu tasarımlarının hazırlandığı modeller muflaya yerleştirilerek akrilik rezinin polimerize olması beklendi. Silikon ölçü zedelenmeden protez çıkartıldı ve protezlerin bitim işlemleri yapıldı.

Tüm overdenture protezler model üzerine sırasıyla yerleştirildi. Pamuk pelet yardımıyla fotoelastik model üzerine makine yağı (Castrol, İstanbul, Turkiye) sürülerek fotoelastik gözlem için model hazır hale getirildi.

Yükleme işlemi yapmadan önce sirküler polariskop (Measurement Group Inc) üzerindeki model fotoğraflandı. Yükleme aleti ile vertikal olarak $135 \mathrm{~N}$ kuvvet tek taraflı olarak sağ birinci molar dişin santral fossasına uygulandı. Gözlenen stres fotoğraflandı (Canon Powershot G3; Canon Inc, Tokyo, Japonya). Tüm fotoğraflar içerdikleri stres çizgilerini belirlemek için görsel olarak değerlendirildi. Stres yoğunluğu ve lokalizasyonu subjektif olarak tek bir araştırmacı tarafından karşılaştırıldı.

Stres seviyelerinin değerlendirilmesinde, stres seviyesi ve fringe sırası arasındaki ilişkiyi gösteren renk skalası ile oluşan renklerin fringe sırasını rakamsal olarak ifade eden çizelge kullanıldı. ${ }^{8}$ Bu çizelgeye göre düşük stres; 1 ya da daha az fringe, orta stres 1 ile 3 arası fringe, yüksek stres 3'ten fazla fringe olarak değerlendirildi.

\section{BULGULAR}

Çalışmamızda kullanılan 3 implant yerleştirilmiş mandibular model üzerinde hazırlanan bar klips tutuculu overdenture protezin fotoelastik stres analizinde, yüklenen taraftaki implantın çevresinde ve ortadaki implantın yüklenen tarafa yakın yüzeyinde orta stres ( $1<$ izokromatik stres çizgileri) gözlendi. Yükleme yapılmayan taraftaki implantın apikal bölgesinde düşük stres (1 $\geq$ izokromatik stres çizgileri) izlendi (Resim 1).

Bar-galvano tutuculu overdenture tasarımında, yüklenen taraftaki implantın çevresinde orta stres ( $3 \geq$ izokromatik stres çizgileri) görüntülendi. Ortadaki implantın orta ve koronal üçlüsünde orta stres (2.5< izokromatik stres çizgileri) saptandı. Ortadaki implantın apikal bölgesinde ve yükleme yapılmayan taraftaki implantın koronal üçlüsünde düşük stres $(1 \geq$ izokromatik stres çizgileri) bulgusuna rastlandı (Resim 1). 


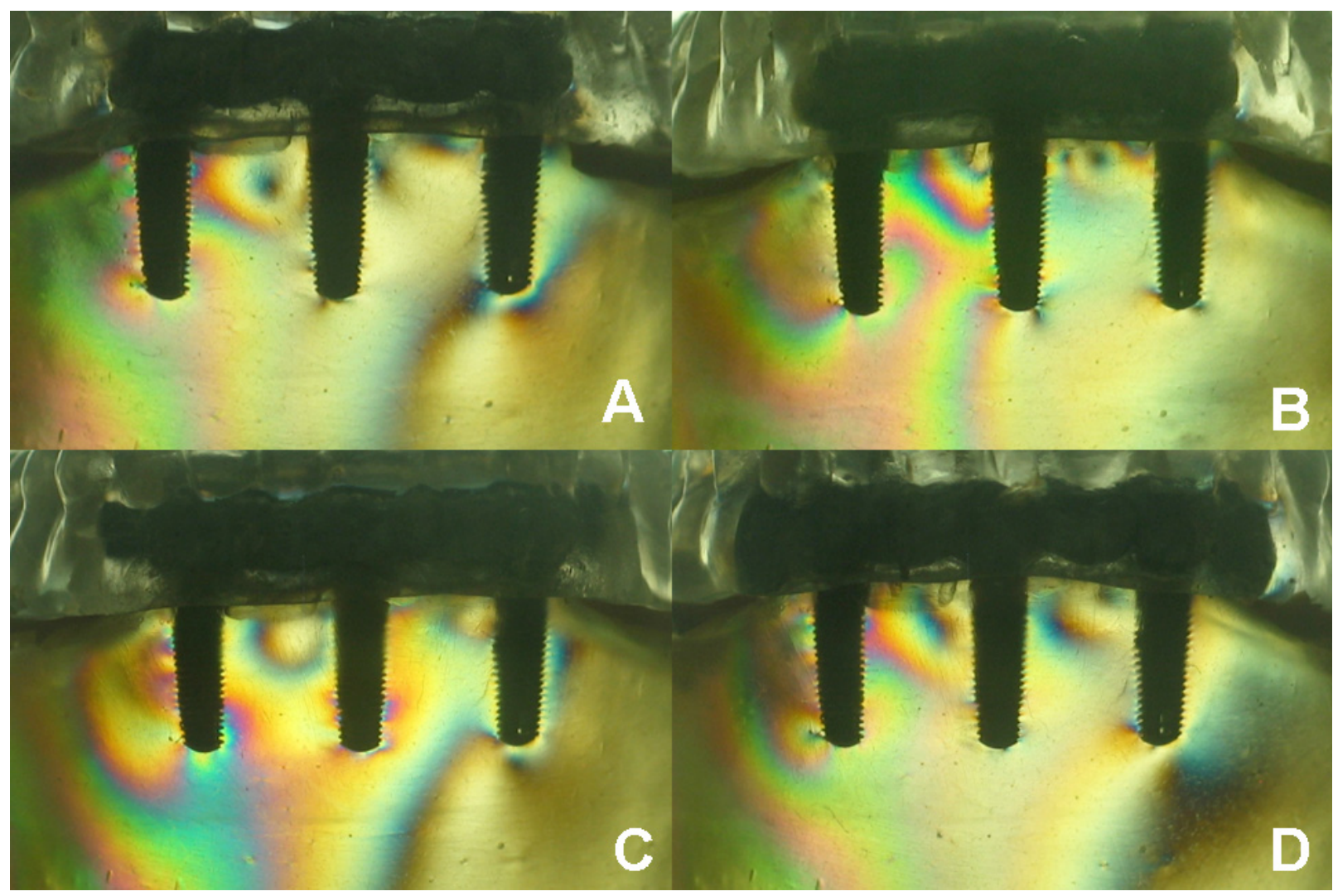

Resim 1. Dört farklı bar tutucu tasarımı (A-D) kullanılan mandibular overdenture modelinde implant çevresinde gözlemlenen stres dağılımı; A: bar klips tutuculu, B: bar-galvano tutuculu, C: bar-locator tutuculu, D: bar-ceka tutuculu.

Bar-locator tutuculu overdenture protezde; yüklenen taraftaki implantın etrafında orta stres $(1.5<$ izokromatik stres çizgileri) izlendi. Ortadaki implantın yüklenen tarafa yakın yüzeyinde ve yükleme yapılmayan taraftaki implantın çevresinde de orta stres $(1<$ izokromatik stres çizgileri) gözlendi. Ortadaki implantın apikal bölgesinde düşük stres ( $1 \geq$ izokromatik stres çizgileri) bulundu (Resim 1).

Bar-ceka tutuculu overdenture tasarımında; yüklenen taraftaki implantın apikalinde orta stres $(2<$ izokromatik stres çizgileri) izlendi. Yükleme yapılan taraftaki ve ortadaki implantların çevresinde ve yükleme yapılmayan taraftaki implantın apikalinde düşük stresle $(1 \geq$ izokromatik stres çizgileri) uygun karakterde izokromatik stres çizgileri gözlendi. Yükleme yapılmayan taraftaki implantın koronal üçlüsünde orta stres ( 1 < izokromatik stres çizgileri) bulgusuna rastlandı (Resim 1).

\section{TARTIŞMA}

İmplant-destekli overdenture protezlerin avantajları dikkate alındığında diş hekimleri tarafından neden sıklıkla tercih edilen bir tedavi yöntemi olduğu anlaşıImaktadır. ${ }^{31,32} \mathrm{Bu}$ tip protezler hem implant hem de protez destek sahalarına oturdukları için gelen yüklerin dengeli bir şekilde dağıtılması önem arz etmektedir. Yüklerin iletimini hassas tutucu tasarımı, implantın yapısı ve destek kemik ile yumuşak doku karakteristiği etkilemektedir. ${ }^{33}$

Aşırı okluzal yükler ve uygun olmayan okluzal kontaklar implantların kaybıla sonuçlanabilecek biyomekanikkomplikasyonlaraneden olabilmektedir. ${ }^{13,14}$ Uygun protez tasarımının yanı sıra dengeli bir okluzyon kurulması da implant ve protez destek sahaları arasında uygun yük dağılımına olanak tanımaktadır. ${ }^{22}$

Bilindiği üzere, ağız içi karmaşık bir biyomekanik sisteme sahiptir. Bu yapının üzerine etki eden kuvvetlerin oluşturduğu streslerin incelenmesinde fotoelastik stres analizi başarılı bir yöntemdir. ${ }^{34}$ Fotoelastik modellerin tek bir rezinden elde edilmesine rağmen, homojen karakterde olmayan mandibuladaki implant ve protezlerin biyomekanik ve stres dağılım özelliklerini incelemek için bu modeller uygundur. 8,9

Mandibular IDO ile ilgili yapılan çalışmalarda iki implanttan destek alınmasının yeterli olduğu iddia edilmektedir. ${ }^{1-3,33}$ Ancak, üç veya daha fazla implantın overdenture desteği için kullanılması tutuculuğu arttırmasının yanı sıra köşeli oturma düzlemi sağlamaktadır. Bununla birlikte, dört veya daha fazla sayıdaki implant kısa bar tasarımlarına neden olacağı için tavsiye edilmemektedir. ${ }^{6}$

Dengeli yük dağılımı için implantların biribirine ve protez giriş yoluna paralel olarak yerleştirilmesi arzu edilmektedir. Fakat bu durum anatomik varyasyonlar 
ve rezidüel kemik topografisi sebebiyle her zaman sağlanamamaktadır. ${ }^{12} \mathrm{Bu}$ yüzden mandibular iDO vakalarında implantlar sıklıkla interforaminal bölgeye y erleştirilmektedir. 2,3,12,21,23 Bu yüzden, çalışmamızda da implantlar interforaminal bölgeye ve birbirilerine paralel olarak yerleştirilmiştir. Distal implantlar köpek dişleri konumuna yerleştirilirken, ortadaki implantın bunlara eşit mesafede olması amaçlanarak tam olarak orta hatta yerleşirilmiştir.

Begg ve ark. ${ }^{35}$ distal implantların açılanmasını $0^{\circ}$, $15^{\circ}, 30^{\circ}$ ve $45^{\circ}$ olarak ayarladıkları dört-implant-destekli fotoelastik modelde stres dağılımını incelemişlerdir. Yapılan bu çalışmada en yüksek stres konsantrasyonun $45^{\circ}$ açılı fotoelastik modelde ve distal implantların çevresinde bulmuşlardır. İmplantların mümkün olduğu kadar biribirlerine paralel olarak konumlandırımasını önermişlerdir ve bu durumda implantların çevresine iletilen yüklerin daha dengeli olacağı çıkarımında bulunmuşlardır. Çalışmamızda da daha dengeli yük dağılımının sağlaması için implantlar birbirine paralel olarak yerleştirilmiştir ve overdenture protez tasarımlarının en uygun şartlarda değerlendirilmesi hedeflenmiştir.

İmplant açılanmalarının stres iletimine olan etkilerini araştıran başka bir in vitro çalışmada, ikiimplant-destekli bar tutuculu overdenture protezler kullanılmıştır. İmplantların birbirine paralel olarak yerleştirildiği modelde stres iletiminin implantların açılı yerleştirildiği modele göre daha dengeli olduğu sonucuna varılmıştır. $^{32}$ Çalışmamızda hazırlanan fotoelastik modelde değerlendirilen overdenture tasarımlarında gözlemlenen en yüksek stres konsantrasyonu orta derecededir.

Çok sayıda hassas tutucu çeşidi diş hekimlerin kullanımına sunulmuş olup, bar ve stud tutucu tipleri ile bunların kombinasyonları overdenture uygulamaları için sıklıkla tercih edilmektedirler.7,10 İmplant-destekli overdenture için en uygun hassas tutucu tasarımının hangisi olduğu ile ilgili herhangi bir uzlaşı henüz bulunmamaktadır. ${ }^{25,26,28,30,36}$

Literatürde farklı bar tipleri değerlendirilerek splintli hassas tutuculardan optimum klinik fayda elde edilmeye çalışılmıştır. ${ }^{12,15,23,37}$ Splintli tasarımların biyomekanik avantaj oluşturabileceği düşüncesiyle ${ }^{12,37}$ çalışmamızda splintli tasarımlar olan bar klips, bar-galvano, barlocator ve bar-ceka tasarımları incelenmiş olup, stres dağılım karakterleri değerlendirilmiştir.

Heckmann ve ark. ${ }^{10}$ rijit teleskop, esnek teleskop, dolder bar, ball ve magnet tutucuları karşılaştırdıkları çalışmalarında rijit teleskop tutucu sisteminin en yüksek momente sebep olduğunu ifade etmişlerdir. Diğer tutucu çeşitlerinin oluşturduğu streslerin normal sınırlar içinde olduğunu vurgularlarken, vakanın durumuna göre hassas tutucunun seçilmesini tavsiye etmişlerdir.

Federick ve Caputo $^{22}$ ERA ve bar-ERA tutucu tasarımlarını karşılaştırmışlar ve stud tutucu tasarımı olan ERA'nın implantlara daha az stres ilettiğini bildirmişlerdir. İmplant bölgesinde stresin az olmasını, gelen yüklerin dişsiz kret sahası tarafından karşılanmasına bağlamışlardır. Bar-ERA tasarımının da stres değerleri güvenle kullanılabilecek sınırlarda bulunmuştur.

Çeşitli hassas tutucu tasarımlarının karşılaştırıldığı bir stres analizi çalışmasında bar tasarımları arasında bar klips tutucu en az strese neden olurken bunu bar-Rk-1 ve bar-ball tasarımları izlemiştir. ${ }^{23}$ Çelik ve Uludağ'ın ${ }^{12}$ yapmış olduğu fotoelastik stres analizi çalışmasında bar-ball tasarımı en az stres oluşturmuştur. İmplantların açılı olarak yerleştirildiği modelde implantların birbirlerine splintlendiği tasarımlar olan bar ve bar-ball tutucu tasarımlarında düşük stres gözlenirken, stud tutucu tasarımlarında orta derecede stres bulgusuna rastlanıldığı bildirilmiştir. Sadowsky ve Caputo $^{37}$ ise ball ve bar tutucu tasarımlarının stres iletim özelliklerini karşılaştırmıştır. Bar tutucu tasarımının ball tutucu tasarımına göre dişsiz kret ve implantlara daha az stres ilettiği sonucuna varmışlardır. Çalışmamızda da benzer şekilde bar klips tutucu tasarımı implantların çevresine en az yükü iletmiştir. Bunu bar-locator, barceka ve bar-galvano tasarımları izlemiştir.

Farklı hassas tutucu tasarımlarının değerlendirildiği başka bir stres analizi çalışmasında bar tasarımları arasında bar klips tutucu en düşük stres değerlerini gösterirken; bar-ball ve bar-Easy Slot tutucu tasarımları bunu izlemiştir. ${ }^{15}$ Çalışmamızda incelenen tutucu tasarımlarının implantların çevresinde oluşturduğu yükler düşük ve orta dereceli olarak gözlemlenmiştir. Çalışmamızdaki tutucu çeşitlerinin hepsi implantdestekli mandibular overdenture tasarımı olarak güvenle kullanılabilir.

\section{SonUç}

Üç-implant-destekli mandibular overdenture protezlerde dört farklı bar tutucu tasarımının değerlendirildiği fotoelastik stres analizi çalışmamızda, test edilen tüm tasarımlarda gözlemlenen en yüksek stres orta derecedir. Protezlere uygulanan yükler, mevcut implantlar arasında paylaşılmıştır ve yükleme yapılan taraftaki implantın çevresine diğer implantlara göre daha fazla stres iletilmiştir. İmplantların çevresinde en az stresin izlendiği tasarım bar klips tutucu tasarımı olmuştur. Çalışmamızdan elde edilen sonuçlar ışığında, bar tasarımlarında tutuculuğu arttırmaya yönelik kullanılan stud tutucu entegrasyonu ve elektroforming gibi yüzey işlemi implantların çevresine iletilen streslerin artmasına neden olabilir. Ancak implantların çevresinde görülen stresler en fazla orta dereceli olduğu için bu tasarımlar vakanın durumuna göre diş hekimleri tarafından güvenle kullanılabilir.

Çıkar çatışması: Yazarlar bu çalışmayla ilgili herhangi bir çıkar çatışmalarının bulunmadığını bildirmişlerdir. 


\section{KAYNAKLAR}

1. Thomason JM, Kelly SA, Bendkowski A, Ellis JS. Two implant retained overdentures--a review of the literature supporting the McGill and York consensus statements. J Dent 2012;40:22-34.

2. Feine JS, Carlsson GE, Awad MA, Chehade A, Duncan WJ, Gizani $\mathrm{S}$, et al. The McGill Consensus Statement on Overdentures. Montreal, Quebec, Canada. May 24-25, 2002. Int J Prosthodont 2002;15:413-4.

3. Thomason JM, Feine J, Exley C, Moynihan P, Muller F, Naert I, et al. Mandibular two implant-supported overdentures as the first choice standard of care for edentulous patients--the York Consensus Statement. Br Dent J 2009;207:185-6.

4. Setz JM, Wright PS, Ferman AM. Effects of attachment type on the mobility of implant-stabilized oveudentures - An in vitro study. Int J Prosthodont 2000;13:494-9.

5. Batenburg RHK, Meijer HJA, Raghoebar GM, Vissink A. Treatment concept for mandibular overdentures supported by endosseous implants: A literature review. Int J Oral Max Impl 1998;13:539-45.

6. Mericske-Stern RD, Taylor TD, Belser U. Management of the edentulous patient. Clin Oral Implants Res 2000;11 Suppl 1:108-25.

7. Heckmann SM, Winter W, Meyer M, Weber HP, Wichmann MG. Overdenture attachment selection and the loading of implant and denture-bearing area. Part 1: In vivo verification of stereolithographic model. Clin Oral Implants Res 2001;12:617-23.

8. Fanuscu MI, Caputo AA. Influence of attachment systems on load transfer of an implant-assisted maxillary overdenture. J Prosthodont 2004;13:214-20.

9. Sadowsky SJ, Caputo AA. Stress transfer of four mandibular implant overdenture cantilever designs. J Prosthet Dent 2004;92:328-36.

10. Heckmann SM, Winter W, Meyer M, Weber HP, Wichmann MG. Overdenture attachment selection and the loading of implant and denture-bearing area. Part 2: A methodical study using five types of attachment. Clin Oral Implants Res 2001;12:640-7.

11. Alsabeeha NH, Payne AG, Swain MV. Attachment systems for mandibular two-implant overdentures: a review of in vitro investigations on retention and wear features. Int J Prosthodont 2009;22:429-40.

12. Celik $G$, Uludag $B$. Photoelastic stress analysis of various retention mechanisms on 3-implant-retained mandibular overdentures. J Prosthet Dent 2007;97:229-35

13. Gotfredsen K, Berglundh T, Lindhe J. Bone reactions adjacent to titanium implants subjected to static load of different duration. A study in the dog (III). Clin Oral Implants Res 2001;12:552-8.

14. Pesqueira A, Goiato $M$, Gennari-Filho $H$, Monteiro D, Dos Santos $D$, Haddad $M$ et al. The use of stress analysis methods to evaluate the biomechanics of oral rehabilitation with implants. J Oral Implantol 2014;40:217-28.

15. Celik G, Uludag B. Effect of the Number of Supporting Implants on Mandibular Photoelastic Models with Different Implant-Retained Overdenture Designs. J Prosthodont 2014;23:374-80.

16. Himmlova L, Dostalova T, Kacovsky A, Konvickova S. Influence of implant length and diameter on stress distribution: a finite element analysis. J Prosthet Dent 2004;91:20-5.

17. Holmgren EP, Seckinger RJ, Kilgren LM, Mante F. Evaluating parameters of osseointegrated dental implants using finite element analysis--a two-dimensional comparative study examining the effects of implant diameter, implant shape, and load direction. J Oral Implantol 1998;24:80-8.

18. Meijer HJ, Kuiper JH, Starmans FJ, Bosman F. Stress distribution around dental implants: influence of superstructure, length of implants, and height of mandible. J Prosthet Dent 1992;68:96-102.

19. Michelinakis G, Barclay CW, Smith PW. The influence of interimplant distance and attachment type on the retention characteristics of mandibular overdentures on 2 implants: Initial retention values. Int J Prosthodont 2006;19:507-12.

20. Doukas D, Michelinakis G, Smith PW, Barclay CW. The influence of interimplant distance and attachment type on the retention characteristics of mandibular overdentures on 2 implants: 6-month fatigue retention values. Int J Prosthodont 2008;21:152-4.

21. Uludag B, Polat S. Retention characteristics of different attachment systems of mandibular overdentures retained by two or three implants. Int J Oral Maxillofac Implants 2012;27:1509-13.

22. Federick DR, Caputo AA. Effects of overdenture retention designs and implant orientations on load transfer characteristics. J Prosthet Dent 1996;76:624-32

23. Tokar E, Uludag B. Load Transfer Characteristics of Various Designs of Three-Implant-Retained Mandibular Overdentures. Int J Oral Maxillofac Implants 2015;30:1061-7.

24. Daas M, Dubois G, Bonnet AS, Lipinski P, Rignon-Bret C. A complete finite element model of a mandibular implant-retained overdenture with two implants: comparison between rigid and resilient attachment configurations. Med Eng Phys 2008;30:218-25.

25. Dashti MH, Atashrazm P, Emadi MI, Mishaeel S, Banava S. The effects of two attachment types on the stresses introduced to the mandibular residual ridge: a 3D finite element analysis. Quintessence Int 2013;44:585-90.

26. Manju V, Sreelal T. Mandibular implant-supported overdenture: an in vitro comparison of ball, bar, and magnetic attachments. J Oral Implantol 2013;39:302-7.

27. Menicucci G, Lorenzetti M, Pera P, Preti G. Mandibular implantretained overdenture: Finite element analysis of two anchorage systems. Int J Oral Maxillofac Implants 1998;13:369-76.

28. Tokuhisa M, Matsushita $\mathrm{Y}$, Koyano K. In vitro study of a mandibular implant overdenture retained with ball, magnet, or bar attachments: comparison of load transfer and denture stability. Int J Prosthodont 2003;16:128-34.

29. Trakas T, Michalakis K, Kang K, Hirayama H. Attachment systems for implant retained overdentures: a literature review. Implant Dent 2006;15:24-34.

30. Takeshita S, Kanazawa M, Minakuchi S. Stress analysis of mandibular two-implant overdenture with different attachment systems. Dent Mater J 2011;30:928-34.

31. Naert I, Quirynen M, Hooghe M, van Steenberghe D. A comparative prospective study of splinted and unsplinted Branemark implants in mandibular overdenture therapy: a preliminary report. J Prosthet Dent 1994;71:486-92.

32. Pigozzo MN, Lagana DC, Sesma N, Souza GF, Ichi AL. Photoelastic stress analysis in mandibular bone surrounding bar-clip overdenture implants. Braz Oral Res 2014;28:1-8.

33. Ochiai KT, Williams BH, Hojo $\mathrm{S}$, Nishimura $\mathrm{R}$, Caputo AA Photoelastic analysis of the effect of palatal support on various implantsupported overdenture designs. J Prosthet Dent 2004;91:421-7.

34. Assuncao WG, Barao VA, Tabata LF, Gomes EA, Delben JA, dos Santos $\mathrm{PH}$. Biomechanics studies in dentistry: bioengineering applied in oral implantology. J Craniofac Surg 2009;20:1173-7.

35. Begg T, Geerts GA, Gryzagoridis J. Stress patterns around distal angled implants in the all-on-four concept configuration. Int $\mathrm{J}$ Oral Maxillofac Implants 2009;24:663-71.

36. Mazaro JV, Filho HG, Vedovatto E, Pellizzer EP, Rezende MC, Zavanelli AC. Evaluation of stress patterns produced by implantretained overdentures and implant-retained fixed partial denture. $J$ Craniofac Surg 2011;22:2153-7.

37. Sadowsky SJ, Caputo AA. Effect of anchorage systems and extension base contact on load transfer with mandibular implantretained overdentures. J Prosthet Dent 2000;84:327-34. 


\section{Evaluation of stress distribution \\ characteristics on various bar designs \\ of three-implant-supported mandibular overdentures}

\begin{abstract}
OBJECTIVE: Implant-supported-overdentures, instead of conventional complete dentures, are frequently recommended to rehabilitate patients having edentulous mandible. The aim of this study was to evaluate the stress distribution characteristics of mandibular implant-supported overdentures with four different bar attachment designs.

Materials AND Method: A photoelastic mandibular model with three implants $(3.75 \mathrm{~mm}-13 \mathrm{~mm})$ placed at the interforaminal region was generated from a cast of an edentulous mandible. Four mandibular bar overdenture
\end{abstract}

designs were fabricated: bar-clip, bar-galvano, barlocator, and bar-ceka. Axial vertical loads (135 N) were applied to the central fossa of the right first molar area for each overdenture design. Stress concentrations were recorded photographically and analyzed visually.

RESULTS: The tested bar attachment designs revealed low and moderate stress levels. The lowest stress was observed with the bar-clip design, followed by bar-locator, bar-ceka, and bar-galvano designs.

Conclusion: The loads were distributed to all of the implants. Studied designs experienced moderate stress levels around the loaded side implant. Bars with distally placed stud attachments and surface treatment with electroforming seems to increase stress levels around the implants.

KEYWORDS: Dental stress analysis; denture, overlay; denture precision attachment; Implant-supported dental prosthesis 